\title{
Review of control strategies for improving the energy flexibility provided by heat pump systems in buildings
}

\author{
Thibault Q. Péan ${ }^{1,2, *}$, Jaume Salom ${ }^{1}$ and Ramon Costa-Castelló ${ }^{2,3}$ \\ 1 Catalonia Institute for Energy Research (IREC), 08930 Sant Adrià de Besòs (Barcelona), Spain \\ 2 Universitat Politècnica de Catalunya (UPC), Automatic Control Department (ESAII), 08028 Barcelona, \\ Spain \\ 3 Institut de Robòtica i Informàtica Industrial (CSIC-UPC), Llorens i Artigas 4-6, 08028 Barcelona, Spain. \\ * Correspondence: tpean@irec.cat; Tel.: +34-933-562-615
}

\begin{abstract}
The present work constitutes a review of the existing literature on supervisory control for improving the energy flexibility provided by heat pumps in buildings. A distinction was drawn between rule-based controls (RBC) and model predictive controls (MPC), given the clear differences in their concept and complexity. For both kinds, the different objectives claimed by these strategies have been reviewed, as well as the control inputs, disturbances and constraints. Notably in MPC, the monetary objective (reduction of the energy costs) has been the most utilized in the literature, therefore the authors advocate for the further study of other objectives related to energy flexibility. Further than the control strategies themselves, the different thermal storage options (necessary to activate the flexibility) have also been reviewed, the built-in thermal mass seeming more costeffective than water buffer tanks in this regard. Based on these conclusions, recommendations for further research topics are drawn.
\end{abstract}

Keywords: demand-side management; heat pump systems; rule-based control; model predictive control; energy flexibility in buildings; literature review.

\section{Introduction}

As the fight against climate change and global warming is becoming more and more urgent, drastic changes are needed in our energy systems. The goal of decarbonization of the market requires that more Renewable Energy Sources (RES) are integrated in the global energy mix. Many nations have understood the emergency and the challenges posed by these requirements, and have fixed quantifiable targets to be achieved in the coming years. For instance, the European Union (EU) requires its 28 member states to reach a share of $20 \%$ of their final energy produced by RES by 2020 , and $27 \%$ by 2030 [1]. Several European countries have set even more ambitious targets, such as Denmark ( $35 \%$ by $2020,100 \%$ by 2050$)$, France ( $23 \%$ by $2020,32 \%$ by 2030$)$, Germany ( $30 \%$ by 2030 ) or Portugal ( $40 \%$ by 2030$)$.

As a result of these ambitions, the sector of renewable energies has considerably grown over the last years. Among others, wind and solar power industries have shown the most dynamics. In fact, the installed capacity of combined solar and wind power have roughly been multiplied by 10 over the last decade [2], the most spectacular increase concerning solar energy, which was almost inexistent in 2005. These two markets are bound to continue developing in the future, pushed by the national policies aforementioned. However and contrary to hydropower which is controllable, solar and wind power possess the characteristic of being variable and sometimes unpredictable. The output of windmills and photovoltaic (PV) panels depend on climatic conditions that vary seasonally, daily or at even higher frequencies (minutes). Furthermore, these weather variations are difficult to know in advance, which complicates the prediction of the amount of electricity production available in the grid.

The variability and unpredictability of renewable energies create threats for the stability of the grid. Indeed, potential mismatch can occur between the supply and the demand, or congestion in some transmission nodes of the grid. A surplus of electricity production can lead to curtailment of renewable plants, while a potential deficit requires the constant availability of peaking power plants to compensate for the lack of renewable energy. Furthermore, distribution infrastructure needs to be 
maintained or upgraded to enable always higher short-term peaks and variations in the grid caused by the increasing number of prosumers [3]. Overall, the traditional vision where the "production follows the demand" needs a paradigm shift towards a concept where the "demand follows the production".

Some solutions in this regard already exist, such as curtailment of renewable plants, supply-side flexibility, adjustment of voltage or frequency in the grid, development of transmission lines. Demand-Side Management (DSM) constitutes another group of solutions, which has concentrated a large amount of research [4]. DSM generally consists in adapting the demand loads to the grid requirements; and this demand profile can be made flexible in different ways: load-shifting, peak shaving, reduction of energy use or valley filling. DSM has historically been applied with larger energy consumers such as industries or factories, which can be subject to rotational load shedding in exchange for monetary compensation. Recently, more research has focused on the DSM potential of smaller users, aggregated or not $[5,6]$. In the present work, attention is drawn to DSM applied to buildings and their embedded systems, heat pumps in particular.

Buildings represent interesting subjects for DSM, first and foremost because they accounted for around 33\% of the total final energy consumption in the world in 2013 [2]. A third of the global energy use represents a great potential if made available for demand response. For this reason, research about energy flexibility in buildings has gained interest in the recent years, even leading to the creation of an Annex project of the International Energy Agency (IEA) on this topic [7]. The experts participating in this work have defined energy flexibility as the "ability of a building to manage its demand and generation according to local climate conditions, user needs and grid requirements".

Within the study of energy flexibility in buildings, the control of smart appliances has been investigated, but heating and cooling loads have maybe concentrated the most interest, because they are the major entry in a building's energy use. Furthermore, the built-in thermal mass constitutes an appropriate storage means to play with the flexibility of heating and cooling loads. However, HVAC systems need to be controlled in a smart manner in order to benefit from these flexibility possibilities, forcing or delaying their operation by the use of the existing thermal storage.

Another reason of the recent interest towards energy flexibility in buildings is the current electrification of dwellings. This trend has notably been pushed by governmental decisions: for instance, the recast of the European Performance of Buildings Directive [8] obliges its member states to only build nZEBs from 2020. The definition of nZEB has long been difficult to clarify with a wide consensus [9], but Sartori et al. [10] proposed a framework definition in 2012. Its basic principles consist in reducing the energy use of the building while providing the remaining with renewable sources, aiming to achieve an annual zero energy balance. Further than this annual balance, the load matching and interaction with the grid should be taken into account in nZEBs, as analyzed by Salom et al. [11-13]. So far, the most promising nZEBs seem to be all-electrical, with a photovoltaic system for the production of the renewable energy part, and a heat pump for the heating or cooling supply (or alternatively biomass)[14]. This combination is up until now the most simple and effective way to reach the nZEB target, and is the most implemented in real cases, as seen for example in the prototype houses presented regularly during the Solar Decathlon competitions [15,16]. In fact, the markets for those two types of systems (PV and heat pump) have seen an important increase over the last years, and this trend is bound to continue. The electrification of residential households will also include in the future the upcoming deployment of electric vehicles.

For all these reasons, buildings equipped with heat pumps are deemed worthy of further investigations with regards to their potential for energy flexibility. They can become active elements in the energy grids, providing flexibility services when needed [17]. A quite extensive amount of research and articles has been published on these topics in the recent years, approximately from the 2010s. Because of the relatively new interest shown on energy flexibility with heat pumps, a clear overview is still lacking in this field, to the knowledge of the authors. Several reviews on close topics have nevertheless been published: Afram and Janabi-Sharifi [18] reviewed MPC techniques applied to HVAC systems, but their study did not focus on heat pumps specifically. Atam and Helsen [19] studied modelling challenges and control techniques, but only for ground-source heat pumps. Fischer and Madani [20] recently published a review on the use of heat pumps within smart grid 
contexts, but their study did not go in depth into the different control strategies used in the studied literature. Based on this assessment, the present article proposes a detailed review of the control strategies used for activating energy flexibility with heat pumps, detailing in particular the different objectives claimed and the constraints included.

In the reviewed publications, a scheme similar to the one presented in Figure 1 was generally observed. The control strategies presented here are acting at the supervisory level, assuming the presence of local controllers within the heat pump, which enable a proper operation of the different components (compressor, pumps, defrost...). The supervisory controller receives information from different sensors in the building (room temperature, temperature in a storage tank, PV production, net power exchange with the grid etc.) as well as data on weather and energy tariffs. Based on this information, the control algorithm defines a strategy for operating the system, and sends the corresponding signal to the local controller in the heat pump.

The control strategies reviewed have been classified in two distinct categories: rule-based controls (RBC) and Model Predictive Control (MPC), because of their conceptual difference. Rulebased controls are simple heuristic methods which generally have the form "if (condition is verified), then (action is triggered)". RBC usually rely on the monitoring of a specific "trigger" parameter (PV power, room temperature for example) on which a threshold value has been fixed. When the threshold is reached, the operation of the heat pump is changed, according to the predefined strategy. On the other hand, Model Predictive Control is a more complex strategy, which relies on a model of the building to project its behavior in the future. MPC is an optimization problem, therefore it intends to find the best solution for the management of the heat pump operation, over a certain time horizon and within certain constraints. Further than this classification between RBC and MPC, the reviewed papers have been sorted by the objective that the control strategy aims for.

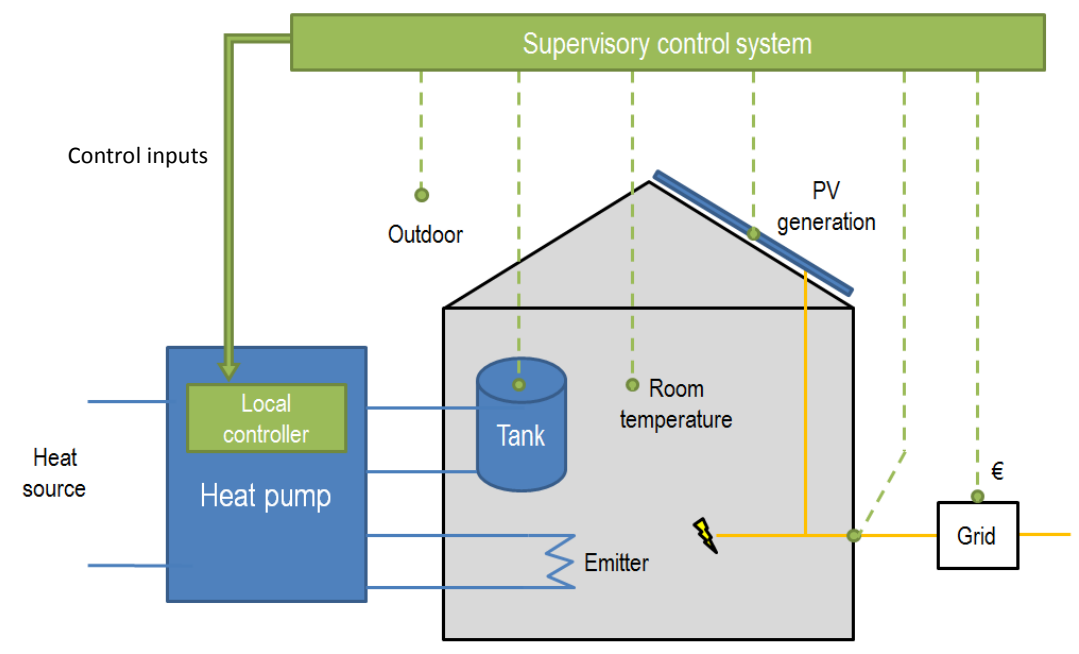

Figure 1. General scheme of supervisory control systems for heat pumps. The supervisory control receives information from different sources, and defines a control input which is then sent to the heat pump.

\section{Common characteristics}

\subsection{Control inputs}

The control strategies act upon certain parameters, which are called control inputs (or manipulated variables). No major differences were found for the control inputs between RBC and MPC. In the reviewed papers, the following control inputs have been identified:

- Temperature set-points: several control strategies modulate the temperature set-points, whether in the room thermostats [21,22], the supply of the systems [23], or in a water storage tank [21,24].

- Power of the heat pump: this variable can be binary, which means the heat pump is completely switched on/off depending on the control algorithm decisions [25]. If the heat pump is invertercontrolled, the power of the heat pump can be modulated by regulating the speed of the 
compressor [26], therefore the control input can vary between the minimum and the maximum available power of the heat pump. This is easily done in simulations, however in practice, this modulation can also be achieved indirectly by adjusting the set-points, like previously mentioned [27].

\subsection{Sensors}

A supervisory control system usually receives measurement data from different sensors. The most common sensors encountered in the literature are the following:

- Temperatures: the indoor temperature is normally the main parameter monitored to ensure comfort. Usually the operative temperature is considered, which is an average between the air temperature and the mean radiant temperature (taking into account the radiation effects from the surrounding surfaces)[28]. When using radiant systems for cooling, the relative humidity must be measured as well to calculate the dew point and thus avoid condensation on the surfaces. In the case of a storage tank, a sensor can measure the water temperature inside it, which is sometimes converted into a "state of charge" of the tank [27,29].

- Power measurements: when applicable, the energy consumption of the building can be monitored, through a simple electricity meter for example. If a production unit like PV is present, the production can usually be retrieved from the inverter. Specific control strategies rely on the measurement of other parameters like the voltage level at the distribution feeder [30].

- Outside conditions: when weather compensation is utilized (see section 2.3), a probe needs to measure the outside temperature to adapt the system supply temperature consequently.

\subsection{Reference weather compensation control}

The simplest type of rule-based control for a heat pump consists in applying a target set-point to its supply temperature. The set-point is then tracked with traditional PID or hysteresis controller [23]. The main objective is therefore to provide the necessary comfort to the end-user, by reaching this set-point. No flexibility is intended at this stage, only the users' needs and the local climate constraints are taken into account, that is why such strategies are normally used as reference cases. As there is no need for supervisory control, a low-level controller integrated in the heat pump is sufficient for the operation of such simple strategies.

Rather than applying a constant set-point, the use of 'heating curves' (also known as 'weather compensation') has become state of the art in most of the heat pumps available on the market. A heating curve enables to adapt the water supply temperature set-point according to the outdoor temperature, and consequently to reduce the energy consumption in part-load conditions. Some parameters are needed as input for the heating curve (conditions at design outdoor temperature and threshold when heating is not anymore needed), which are often determined in practice by trial and error [22].

Several authors mention the use of weather compensation control in the reference case of their publications $[23,27,29,31,32]$. The set-point obtained from the heating curve can be applied in a water storage tank or directly in the water circulated into the heating circuit of a building (radiators, floor heating). A room thermostat is then necessary to control the water flow (either from the tank or directly from the heat pump) or heat pump activation and deliver the proper amount of heat to the building zone, according to the occupancy.

\section{Rule-based controls}

\subsection{Classification of rule-based controls}

When the building's designers intend to provide some flexibility from the building side, further than only comfort, they usually define certain objectives to reach. Especially in RBC, these objectives are not always mentioned explicitly, but most of the time a clear goal can still be identified. In the present review, the following objectives have been identified: load shifting with fixed scheduling, peak shaving, reduction of energy cost and increasing the consumption of renewables. These are 
summarized in Table 1 and detailed in section 3.2. Most of these rule-based controls follow the same principle: a trigger parameter is monitored (time, power, energy price, residual load) and associated with predefined threshold values. When the threshold is reached, it triggers a control action on the heat pump (start/stop or change in set-point among others).

Table 1. Classification of rule-based controls according to their objectives and trigger parameters.

\begin{tabular}{|c|c|c|}
\hline Flexibility objective & References with rule-based control (RBC) & Trigger \\
\hline $\begin{array}{l}\text { Load shifting with fixed } \\
\text { scheduling }\end{array}$ & $\begin{array}{l}\text { Lee et al. (2015)[21]; Carvalho et al. (2015)[33]; De Coninck et al. (2010)[29]; } \\
\text { De Coninck et al. (2014)[30] }\end{array}$ & Time \\
\hline $\begin{array}{l}\text { Peak shaving, reduction } \\
\text { of peak power exchange }\end{array}$ & $\begin{array}{l}\text { Dar et al. (2014)[27]; De Coninck et al. (2010)[29]; De Coninck et al. } \\
\text { (2014)[30] }\end{array}$ & Power \\
\hline Reduction of energy cost & Schibuola et al. (2015)[34]; Le Dréau and Heiselberg (2016)[35] & Electricity price \\
\hline $\begin{array}{l}\text { Increase consumption of } \\
\text { renewables }\end{array}$ & $\begin{array}{l}\text { Dar et al. (2014)[27]; Schibuola et al. (2015)[34]; De Coninck et al. (2014)[30]; } \\
\text { Reynders et al. (2013)[32]; Miara et al. (2014)[24]; Hong et al. (2012)[22] }\end{array}$ & $\begin{array}{l}\text { PV power, voltage } \\
\text { deviation, residual } \\
\text { load }\end{array}$ \\
\hline
\end{tabular}

\subsection{Flexibility objectives}

Load shifting with fixed scheduling is maybe the most evident form of rule-based control for energy flexibility. Daily peak periods can usually be identified in a national electricity grid. The controller can therefore try to avoid or force the operation of the heat pump during fixed hours. For instance, Lee et al. [21] use set-point modulation to reduce the use of the heat pump during the grid peaks (14:00 to 17:00 in summer and 17:00 to 20:00 in winter). They achieved a reduction in the energy consumption during peak hours of $80 \%$ and $64 \%$ in cooling and heating respectively (Figure 2 (a)). Carvalho et al. [33] forced the heat pump to stop during peak hours (9:00 to 10:30 and 18:00 to 20:30), reducing the energy cost by 17 to $34 \%$ (Figure 2 (b)). Fixed scheduling can also be used to force the charging of a thermal energy storage (TES) tank: for instance, [29] used this strategy to charge a tank from 12:00 to 19:00 every day, benefitting from the higher Seasonal Performance Factor (SPF) of the heat pump during daytime. [30] also used clock control, raising the Domestic Hot water (DHW) heating set-point from 12:00 to 16:00 in order to force the heat pump operation during this period, and achieving best results than more advanced rule-based controls. Overall, fixed scheduling strategies are simple and easy to implement, and they can already achieve a substantial performance. Even though the schedule can be changed seasonally for instance [21], this method is not dynamic enough (the fixed schedule does not adapt to the real conditions).

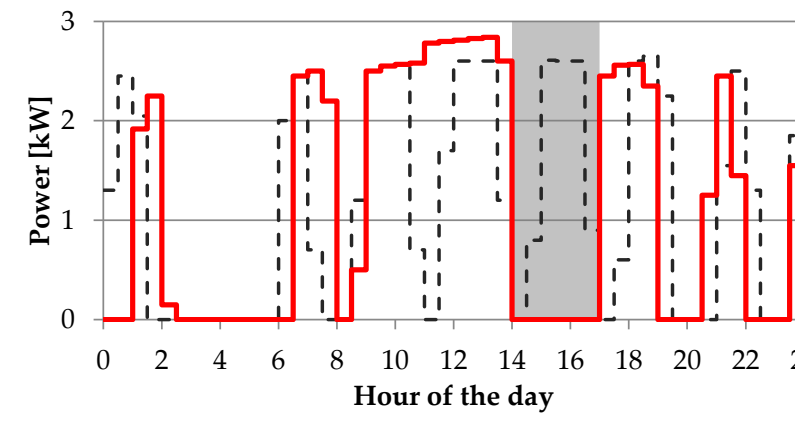

(a)

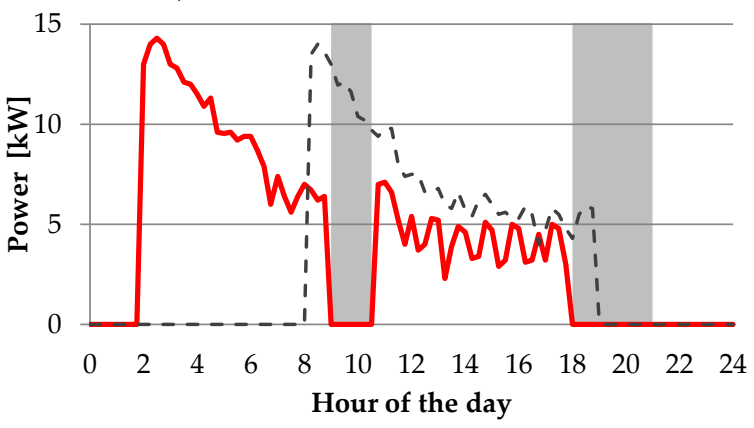

(b)

Figure 2. Examples of fixed scheduling strategies from [21](a) and [33](b). The peak periods (identified in grey) are constant, and the control strategies thus aim to avoid the heat pump operation (red lines) during these fixed periods. In both cases, this objective is reached. The dashed lines show the profile of the heat pump operation prior to the implementation of the control.

Another objective targeted by RBC strategies is peak shaving, i.e. the reduction of the demand peak, in order to support the grid operation. In these cases, the monitored parameter is the power 
exchange of the building with the grid. Thresholds can be defined both for the export and in the import powers, or only in one of them. For instance, [27] set an import limit of $2500 \mathrm{~W}$ and an export limit of $5000 \mathrm{~W}$ in a nZEB equipped with a PV system. When the building is consuming more than the import threshold, the heat pump is switched off. Conversely, if the building injects more power in the grid than the export thresholds, the heat pump is started. This control method results in a reduction of the import hours (over the threshold limit) down to 41-108 hours, compared to 346 hours for the reference case. Reference [29] presents a similar "grid-load strategy", with both consumption and injection thresholds set at $3500 \mathrm{~W}$. This method could reduce the number of peaks by up to $50 \%$ and the one percent peak power (mean power of the one percent highest quarter hourly peaks) by up to $20 \%$. However, the highest peaks could not be eliminated, since they were not caused by the heat pump nor the PV systems, but by non-controllable loads such as domestic appliances. In a later study, De Coninck et al. [30] investigated a similar approach, but applied to a cluster of 33 buildings instead of a single one. When the power injection in the grid surpasses the predefined limit, the set-points for the DHW tanks are raised, thus increasing the self-consumption from the PV systems. This strategy reduces effectively the curtailing losses, though not as much as the fixed scheduling strategy also investigated in [30] (because the latter is active every day and not only during sunny days). To sum up, peak shaving control strategies enable to support the grid by limiting the peak demand or injection of the building. Another conclusion drawn from the review is that the threshold values should be chosen with precaution, since their setting will highly influence the outcome of the control strategy.

Certain control strategies rely on the variations of energy price in time with the objective of reducing the energy costs for the end-users. As evidenced notably by [36,37], time-varying price structures produce incentives for the consumers to shift their loads or reduce their peak demand, while reducing their energy budget. It is therefore profitable for both parties, the grid side and the consumer side. In this case, the controller monitors the electricity price and takes action when the price becomes too high or too low. The main differences in the reviewed papers therefore consist in the definition of the high and low price thresholds. Schibuola et al. [34] propose two different approaches: the first one analyzes the price data of two entire years (2012 and 2013), and fixes thresholds based on this distribution. The second approach compares the current electricity price with the forecasted price over the next 12 hours, hence relying on prediction data rather than on past data. Both methods enabled to reduce the yearly electricity costs of around $15 \%$. Le Dréau and Heiselberg [35] also based their approach on recorded past data: their thresholds were calculated using the first and the third quartiles from the price distribution of the two weeks prior to the current moment. Changes of $\pm 2 \mathrm{~K}$ in the heating set-points were then implemented when the current electricity price reached the thresholds. A high flexibility was thus obtained and the cost savings ranged from 3 to $10 \%$. This type of price-based control is bound to grow in the coming years with the increasing development of smart-grids, where dynamic pricing can easily be sent to the end users. The performance of the controls then highly depends on the processing of this price data and the definition of the threshold parameters.

The last category of rule-based controls reviewed here aims at improving the consumption of renewable energy sources (RES). This can be done at the scale of the building, which means a local generation unit is present and the objective consists in improving its self-consumption. It can also be done at the scale of the overall electricity grid, which means the control relies on the analysis of the residual load calculated at a national level. The residual load equals the power demand less the power generation from fluctuating RES (solar and wind), hence representing the electricity demand not covered by renewables. In the study [27], the building is equipped with a PV system. The controller starts the heat pump when the PV production exceeds the non-heating loads. This method leads to an improvement of the load cover factor from 19.6 to $26-32 \%$, hence a better coincidence between photovoltaic generation and electricity consumption of the heat pump. A similar approach is presented in [34], but with a more straightforward method: the heat pump is simply forced to switch on when the PV panels are generating electricity, regardless of the current loads. This method enabled to reduce the electricity exported by up to $12 \%$ and the electricity imported by up to $22 \%$, thus improving the self-consumption. [30] use a different trigger for the activation of DSM: voltage 
measurement. Their study assumes that an excess PV production induces an increase of voltage of the distribution feeder. The voltage is therefore monitored, and when it surpasses a defined value (around $250 \mathrm{~V}$ ), the set-point for the DHW tank is raised in order to utilize more electricity and avoid the PV inverter shutdown. This method enables to reduce the curtailing losses by up to $74 \%$. The residual load at a national scale has been identified by [38] as a potential input signal for DSM control of heat pumps. [24] makes use of this residual load profile to design their own Time of Use (ToU) signal. This technique enables an efficient load shifting: the percentage of energy spent during the most profitable periods (e.g. with high residual load) is increased from $30 \%$ to around $60 \%$ in the best case. To conclude, the improvement of RES consumption can be realized by monitoring different trigger parameters: voltage at the distribution feeder, PV production, residual load at the local or global scale, but it remains difficult to compare these approaches since they use different evaluation criteria.

\subsection{Interaction with constraints}

Rule based controls also need to deal with additional constraints, to account for the comfort of users or the physical limitations of the systems. Similarly than the control objective, the constraints are more difficult to identify in the case of RBC, since they are not always formally identified. For instance, setting a threshold on the grid power exchange as presented in $[27,29,30]$ could be considered as a constraint on this parameter (or alternatively as a peak shaving objective, as mentioned previously).

Control inputs are usually constrained by construction, therefore these constraints are normally always satisfied. For instance, the temperature set-points are obviously chosen within the desired comfort boundaries during occupancy periods. It is however more difficult to ensure that the constraints on the control outputs will always be formally fulfilled. In the case of building climate control, the control outputs almost always include the room temperature. For instance in [33], a preheating strategy is implemented and the heat pump is switched off during peak hours. The authors do not mention a backup control strategy for ensuring comfort during this switched off period. Even though the preheating strategy is specially designed to avoid discomfort, such punctual inconveniences could occur.

In several publications, a buffer storage is present. Such device enables to decouple the zone heating circuit from the buffer heating circuit. In this way, the fulfilment of the constraints on the zone temperature is less affected by the flexibility-oriented RBC: the zone heating circuit operates normally, retrieving thermal energy from the storage, while the flexibility strategy is applied directly on the storage. In this case, additional constraints can be applied to maintain a minimum or maximum state of charge (SOC) in the storage $[24,27,29]$.

In general, constraints in RBC can be seen as additional rules which are given priority over the rule defining the flexibility objective. The physical integrity and the satisfaction of users must normally be met at all times, and the flexibility can be improved only once these constraints are satisfied. This principle is well illustrated in the form of a flow chart in [22]: the algorithm first checks if the zone temperature lies between the upper and lower comfort boundaries. If and only if this condition is satisfied, the flexibility strategy can be started. Even if favorable conditions appear (i.e. high production of renewables) while comfort is not guaranteed, the controller will still operate the system normally to promptly return within the defined temperature boundaries, before to consider the activation of flexibility.

Several RBC strategies use modulation of temperature set-points as the main driver for energy flexibility $[21,35,39]$. If these set-points are always chosen within the desired comfort boundaries (considering the dead-bands too), the output temperature should also stay within these boundaries (unless the system is badly dimensioned or has too much inertia). With this technique, the comfort constraints are fulfilled while the loads are shifted in time.

To sum up, in the case of RBC, the fulfilment of constraints is difficult to guarantee, given the lack of tools to formally analyze the system behavior. Furthermore, rule-based controls do not allow to balance the satisfaction of the constraints with the desired objective (and thus to allow for instance 
small constraint violations if it provides greater benefits for the achievement of the objective). However, the rules are normally designed to guarantee constraints fulfilment and thus ensure a satisfactory performance of RBC.

\subsection{Conclusions and limits of $R B C$}

In view of the presented papers and their respective conclusions, it is observed that rule-based controls can yield significant performance with regards to improving the energy flexibility. Applying simple heuristic algorithms enables for example to delay the use of a heat pump for several hours, or to realize significant cost savings by reorganizing its operation schedule. The good performance of the heuristic control strategies obviously depends a lot on the good choice of the thresholds values placed on the "trigger" parameters [40]. It is therefore crucial to draw some attention on the tuning of these values, as highlighted also by [41].

Another advantage of RBC resides in its simplicity. No complex models are required, neither computationally demanding algorithms. Most of the reviewed papers consider algorithms of the form "if condition is fulfilled" then "send a signal to the heat pump". This simplicity could consequently facilitate the potential implementation of such controls at a larger scale, having a greater impact ultimately.

However, rule-based controls also feature several lacks, usually concerning their poor dynamics. The fact that the trigger parameters or threshold values are fixed makes it difficult for this kind of control to adapt to changing external conditions. For instance, the study [21] uses fixed scheduling because the peaks in the grid are identified between 17:00 and 20:00 in winter days. However, this assumption is based on the analysis of previous data and rules of thumb, but it could very well happen that the peaks occur outside this time window. This will become truer and truer in the future, as the penetration of variable renewable energies increases in the overall mix: Klein et al. [38] predicted that the variability of the residual load will be substantially higher in 2030. In particular in Spain, the calculated standard deviation of the residual load was very high compared to other countries, which means that the profile of this residual load could vary drastically from one day to the next. For this reason, the performance of fixed-rule controls appears rather limited, and better control strategies are needed in order to react faster to rapid changes in the grid conditions.

Finally, rule-based controls lack the possibility to anticipate and optimize the heat pump operation over a certain time horizon. This deficiency is clearly visible when analyzing the result graphs from [22] presented in Figure 3: the rule-based control implemented here results in a better fit of the demand power curve to the supply power curve (wind turbine), which is a good example of demand flexibility. However, a peak of electricity generation occurs just before the start of the heating system, but it is not exploited by the controller. A more optimal strategy would have preheated the building before, benefitting from the availability of electricity at that moment, and limiting the impact on the occupants' comfort afterwards. Another example of these deficiencies is given by [32]: in midseason, their control strategy charges the thermal mass of the building in the morning, because the local PV system produces electricity at that time. The building therefore reaches the upper limit of temperature comfort, and when the solar gains (unanticipated by the control strategy) later enter the room, overheating occurs.
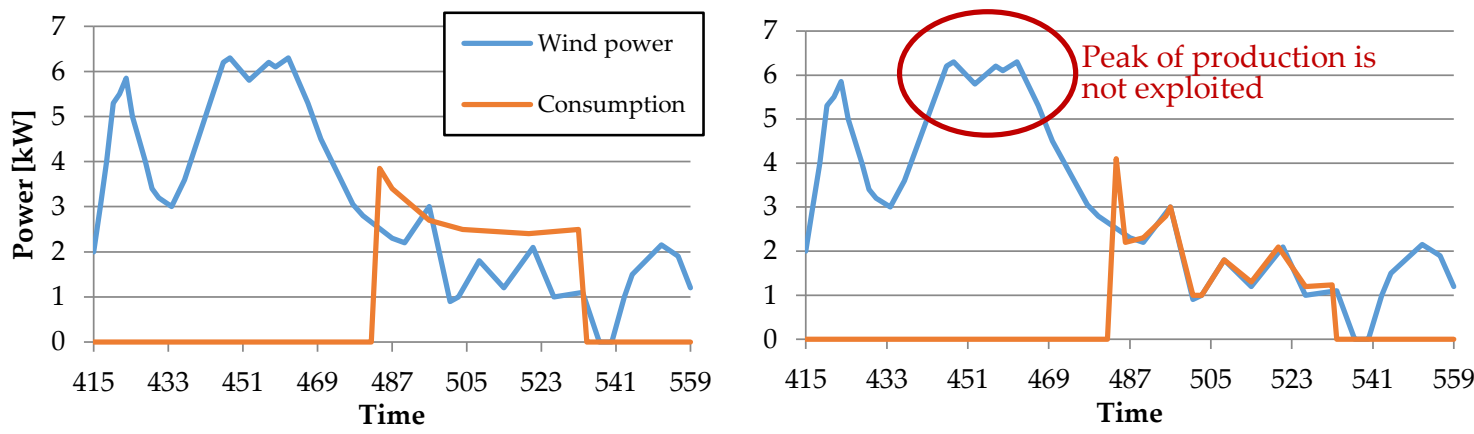
Figure 3. Results extracted from the rule-based control algorithm proposed by [22]. The reference case is presented on the left and the rule-based control on the right. The rule-based control clearly provides a flexibility of the demand, since the consumption (orange line) adapts to the production (blue line). However, it does not optimize the energy management: the production peak before the activation of the heat pump is not exploited for storing energy, since the rule-based control is unable to make anticipated decisions.

With this review, the performance and simplicity of rule-based controls have been highlighted, as well as the importance of a good design in the choice of the parameters defining the rule. It should be mentioned that it remains difficult to evaluate the performance of RBC, since they usually do not define an explicit cost a priori. Furthermore, their lacks in dynamics, adaptation and anticipation call for better control strategies based on optimization methods, as will be presented in the next section.

\section{Model Predictive Controls}

\subsection{Classification of MPC and decomposition of the different objective functions}

Even though rule-based controls can already yield significant improvements with regards to demand response and flexibility, MPC is expected to produce further improvements but it also requires more investments and is more complex due to the prior need of a model [30]. As recalled by [42], model predictive control covers a wide range of different control techniques. They have in common to "make explicit use of a model of the process to estimate a future control signal by minimizing an objective function" over a receding horizon $N$. At each time step $k$, the best sequence of future control inputs is calculated by the optimizer, and only the first one is then applied to the actual systems. The case of an application of MPC to building climate control with MPC is presented schematically in Figure 4.

The first applications of MPC to building climate control intended to enhance the energy efficiency and reduce the energy consumption [43], without too much focus on flexibility or demandside management. Recently, more research has been developed for the use of MPC within smartgrids, with emphasis on flexibility. In this regard, MPC is an ideal framework to use weather and price predictions in order to make use of the thermal storage of a building appropriately [40].

In MPC (and contrary to RBC), the objective of the controller is relatively simple to identify due to the presence of an explicit cost function. Its expression represents the quantity that the control should optimize, for instance the energy cost. In general, this function contains multiple terms that represent multiple objectives, which are balanced with appropriate weights. The optimal values of the weighting factors are usually computed using Pareto fronts, such as mentioned in [44]. Table 2 summarizes the objective terms used in the referenced papers (see also detailed table in the Appendix), and indicates whether the studies rely on simulation or experimental work. It can thus be observed that few articles have validated the performance of their control strategies through experimental implementation; most of them only rely on computer simulations.

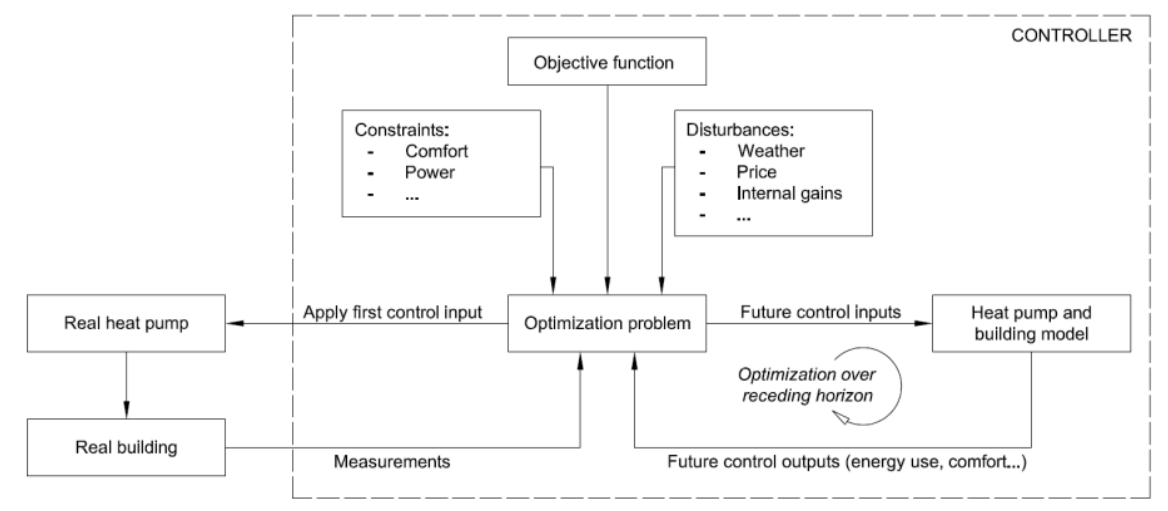

Figure 4. Principle of MPC applied to building climate control with heat pumps, partially derived from [40] and [45]. The controller finds the sequence of future control inputs that will minimize the objective function over the receding horizon, taking into account the constraints, disturbances, and behavior of the model. The first control input is then applied to the real system. 
Table 2. Decomposition of the objective functions in MPC strategies. A more detailed version of this table can be found in the Appendix, with the mathematical formulations of the different terms. Furthermore, it is indicated in the left column if the MPC strategy has been tested with simulations, experimentally, or both.

\begin{tabular}{|c|c|c|c|c|c|c|c|c|}
\hline & Reference & $\begin{array}{c}\text { Economic } \\
\text { term }\end{array}$ & $\begin{array}{c}\text { Energy } \\
\text { term }\end{array}$ & $\begin{array}{c}\text { Peak } \\
\text { shaving } \\
\text { term }\end{array}$ & $\begin{array}{l}\mathrm{CO}_{2} \\
\text { term }\end{array}$ & $\begin{array}{c}\text { Robustness } \\
\text { term/slack } \\
\text { variable }\end{array}$ & $\begin{array}{l}\text { Flexibility } \\
\text { term }\end{array}$ & $\begin{array}{l}\text { (Dis)comfort } \\
\text { term }\end{array}$ \\
\hline \multirow{14}{*}{ 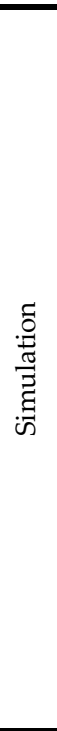 } & Masy et al. (2015)[31] & $\mathrm{x}$ & & & & & & $\mathrm{X}$ \\
\hline & Tahersima et al. (2012)[46] & $x$ & & & & & & $x$ \\
\hline & Li and Malkawi (2016)[47] & $x$ & & & & & & $x$ \\
\hline & Verhelst et al. (2012)[44] & $x$ & & & & & & $x$ \\
\hline & Pedersen et al. (2013)[48] & $x$ & & & & & & $x$ \\
\hline & Kajgaard et al. (2011)[49] & $x$ & & & & $x$ & & $x$ \\
\hline & Halvgaard et al. (2012)[50] & $x$ & & & & $x$ & & \\
\hline & Santos et al. (2016)[51] & $x$ & & & & $x$ & & \\
\hline & Bianchini et al. (2016)[52] & $x$ & & & & & $x$ & \\
\hline & $\begin{array}{l}\text { Knudsen and Petersen } \\
(2016)[53]\end{array}$ & $x$ & & & $x$ & & & \\
\hline & Sichilalu et al. (2015)[54] & $x$ & & & & & & \\
\hline & $\begin{array}{l}\text { Mendoza-Serrano et al. } \\
(2014)[55]\end{array}$ & $x$ & & & & & & \\
\hline & $\begin{array}{l}\text { Salpakari and Lund } \\
\text { (2015)[56] }\end{array}$ & $x$ & & & & & & \\
\hline & Toersche et al. (2012)[57] & & & $x$ & & & & \\
\hline \multirow{3}{*}{$\begin{array}{l}\text { 吾 } \\
\text { D }\end{array}$} & Ma et al. (2014)[58] & $x$ & & $x$ & & & & \\
\hline & Sturzenegger et al. (2013)[59] & & $x$ & & & & & \\
\hline & Oldewurtel et al. (2013)[60] & & $x$ & & & & & \\
\hline \multirow{2}{*}{ 齐 } & De Coninck et al. (2016)[61] & $x$ & & & & & $x$ & $x$ \\
\hline & Vana et al. (2014)[62] & $x$ & & & & $x$ & & $x$ \\
\hline
\end{tabular}

\subsection{Economic $M P C$}

In the reviewed literature, one sort of MPC clearly stands out: Economic MPC (EMPC), where the objective is to reduce monetary costs. This cost optimization relies on time-varying energy prices. The objective function $J_{e}$ has in most of the cases indexed in Table 2 the following form:

$$
J_{e}=\sum_{k}\left[P_{e l}(k) \cdot W_{h p}(k)+\sum_{i} P_{i}(k) \cdot G_{i}(k)\right]
$$

Where $k$ is every time step from 0 to the receding horizon $N, W_{h p}$ is the control input (the heat pump power in this case), $P_{e l}$ is the electricity price (varying in time according to different tariffs). When several energy carriers $i$ are present, their respective price $P_{i}$ and consumption $G_{i}$ are also taken into account. The optimization process then must minimize this cost function over the receding horizon, logically leading to monetary savings. Even though the claimed objective is to reduce the costs, this method will normally result in load shifting towards periods of lower energy prices. Depending on how the price profile is constructed, this load shifting can constitute an interesting form of energy flexibility, and therefore a more general objective. The price profiles tested either have a day/night structure $[26,31,47,54,61]$, or an hourly variation corresponding to the spot prices on the day-ahead market (often the Nordpool market for instance)[30,31,49,50,52,53].

[31] use EMPC precisely to compare three different electricity tariffs: flat rate, day-night tariff and ToU (see Figure 5, (a)). Constraints are implemented for the output temperature range and the maximum power of the heat pump. It is clear from the middle graph of Figure 5 (a) that the electricity consumption of the heat pump is shifted to low-price hours when a time-varying price is applied. At the optimum, this load shifting reaches $80 \%$, while the procurement costs are reduced by up to $15 \%$. However, an increase in the overall energy consumption of $20 \%$ is observed. 

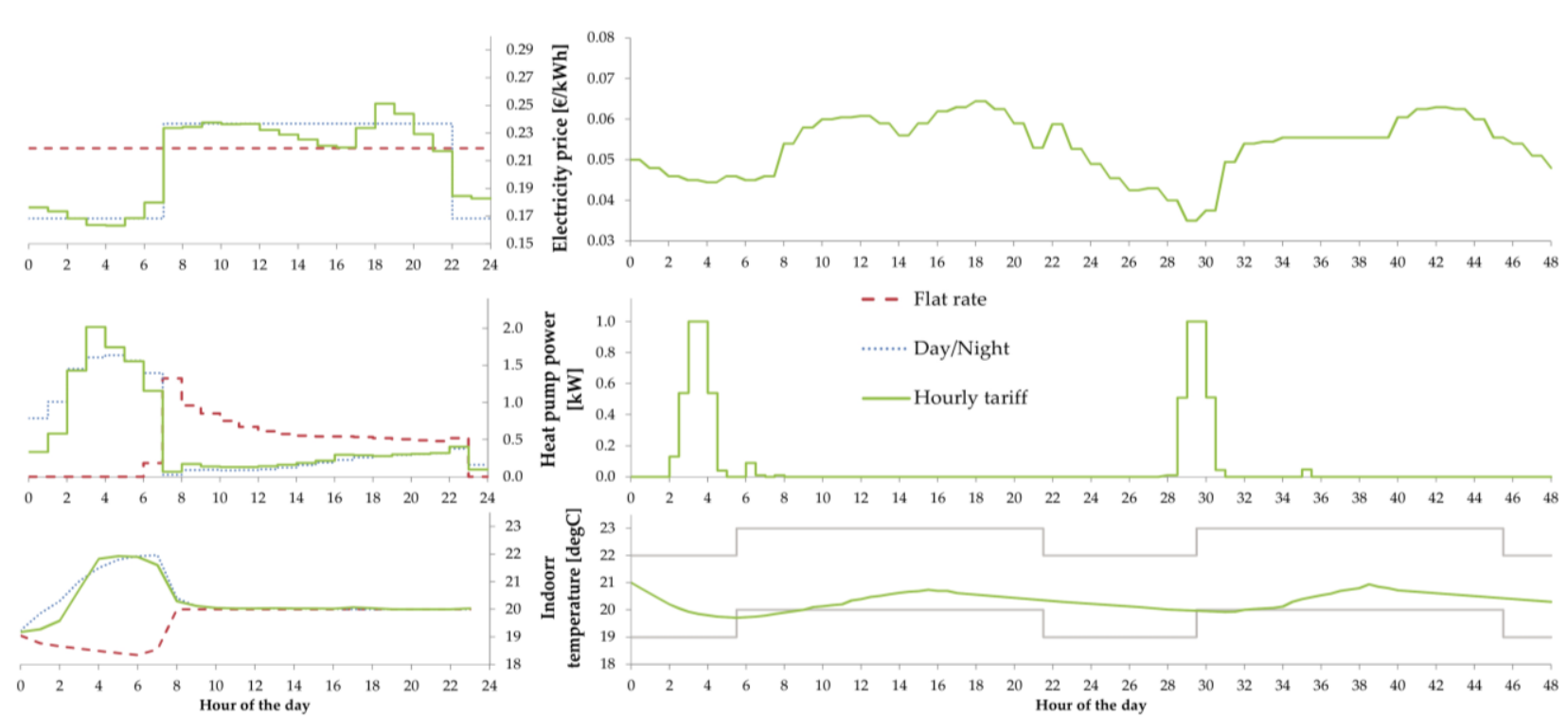

(a)

(b)

Figure 5. EMPC examples from (a) Masy et al. (2015)[31] and (b) Halvgaard et al. (2012)[50]. The top graphs show the electricity price variations (on the left, three different tariffs were tested). The middle graphs show the resulting heat pump power profiles, and on the bottom graphs, the resulting indoor temperature profiles. A coincidence is observed between the utilization of the heat pump and the periods of lower energy price.

[61] used a very similar method. A major difference is that the building here is equipped with a gas boiler and a heat pump, therefore the system can alternate between both sources, depending on their cost. In the summation of $J_{e}$, the cost of gas is implemented through the additional term $P_{g}(k)$. $G_{g}(k)$, with $G_{g}$ the gas consumption and $P_{g}$ the constant price of natural gas (similar method in [47]). Furthermore, this study is experimental and measures the effects of the control strategy on a real building. A reduced-order model and a day-night electricity tariff were used. Compared to RBC, the MPC enabled to reduce the costs by $30-40 \%$, and the primary energy by $20-30 \%$, which is an additional benefit since this parameter is not included in the objective function. To achieve this result, the MPC controller tends to preheat the building with the heat pump during the night at a lower supply temperature, and enhances the use of the heat pump as a priority over the gas boiler.

[50] also present an EMPC scheme. The studied house is heated by floor heating supplied by a ground-source heat pump (GSHP) which is linked to a storage tank, and is represented by a single zone state-space model. The EMPC strategy minimizes the electricity cost while keeping constraints of indoor temperature, by acting on the power used by the compressor of the heat pump. The method resulted in 35\% economic savings, compared to a case with constant electricity price. The energy consumption is clearly shifted towards low-price periods as can be seen in Figure 5 (b).

\subsection{Other flexibility objectives}

Aside from EMPC, MPC has sometimes been used with other flexibility objectives than the sole monetary one. For instance, [59] used an MPC strategy to control a Swiss office building's HVAC systems (including thermal slab, ventilation and blinds). The goal of the objective function is to minimize the non-renewable primary energy (NRPE) consumption, through the following formulation:

$$
J_{q}=\sum_{k} c(k) \cdot u(k)
$$

Where $u(k)$ is the vector of the control input and $c(k)$ is a vector representing the conversion factors ("cost") of each control input, depending on the systems efficiency. MPC used 17\% less NRPE energy (including lighting and equipment energy consumption) compared to an RBC strategy, most savings occurring during the heating season. 
[32] used a model-based predictive control approach, but not formulated explicitly as an optimization problem. The controller defines the heating set-point $T_{\text {set }}$ according to the following equation: $T_{\text {set }}=T_{\min }+1 / C \cdot \int_{0}^{N} Q_{\text {pred }}(t) d t$, where $T_{\min }$ is the minimum temperature for comfort, and $C$ is the thermal storage capacity of the building. The model and prediction aspects of the controller are present within the term $Q_{\text {pred }}(t)$ which is the predicted heating demand, computed using detailed building model simulation, assuming perfect prediction of weather and future internal gains. The aim of the set-point calculation is to preheat the building taking into account the future energy demand, thus avoiding overcharging. In this way, the electricity use of the heat pump during peak period is reduced by 47 to $88 \%$, depending on the cases.

Few articles use a term for peak shaving within their objective function. Notably [58] present the following formulation:

$$
J_{p}=P_{p} \cdot \max _{k}\left\{W_{h p}(k)\right\}
$$

Where $P_{p}$ represents the peak demand cost. In this way, the peak power is penalized in the objective function, therefore the MPC will try to reduce it, leading to peak shaving. Unfortunately in [58], the authors do not analyze the results in terms of peak shaving. [57] use a different formula, where $J_{p}$ is the difference in heat pump power between time steps $k$ and $k+1$, summed over the control horizon. By minimizing it, the power curve is smoothed, resulting in $25 \%$ lower peaks.

Reducing the $\mathrm{CO}_{2}$ intensity is an alternative objective implemented in MPC. [53] notably use the same formulation than $\mathrm{J}_{\mathrm{q}}$ in Eq.(2), except that the cost vector $c(k)$ here represents the prediction of the $\mathrm{CO}_{2}$ intensity associated with the electricity production. An MPC solely aiming at minimizing this term reaches effectively a reduction of $\mathrm{CO}_{2}$ emissions, but only reduces costs marginally and can potentially increase consumption in peak hours, in contrast to an EMPC.

Other terms can be introduced in the objective function to increase the robustness of the control. They do not represent a flexibility objective in their own, but enable a smoother operation of the systems. [51] for example introduce the following term:

$$
J_{r}=\sum_{k} \rho \cdot v(k)
$$

Where $\rho$ is a penalty factor and $v(k)$ a slack variable [45]. The constraint on the room temperature is then formulated as follows: $T_{\min }-v(k) \leq T_{\text {zon }} \leq T_{\max }+v(k)$. Without the slack variable, the MPC could not find a solution if the output $T_{z o n}$ accidentally exceeds the constraint boundaries $\left[T_{\min }, T_{\max }\right]$. Introducing the slack variable enables to soften the constraints imposed on the output, and thus the optimizer can find a solution outside the strict range, although at the cost of a certain penalty $[50,62]$. It therefore enlarges the feasible range of the problem.

In one article [61], the authors introduce directly a term for energy flexibility in the objective function:

$$
J_{f}=\left(\sum_{k=k_{i}}^{k_{e}} W_{h p}(k) \cdot k-E_{\text {target }}\right)^{2}=\left(E-E_{\text {target }}\right)^{2}
$$

Where the optimizer should track a pre-defined energy consumption $E_{\text {target }}$ during a specified flexibility interval $\left[k_{i} ; k_{e}\right]$. In this scenario, a third party (energy provider for example) requires the activation of energy flexibility during a certain period $\left[k_{i} ; k_{e}\right]$. If the required flexibility consists in increasing the energy consumption, $E_{\text {target }}$ can be set to high value, while if it consists in limiting the energy consumption during the time interval, $E_{\text {target }}$ can be set to zero.

Finally, it is important to mention that these different objectives are usually combined in a single objective function. Most papers use linear combinations of the different $J$ terms, setting different weights to put more emphasis on certain aspects of the optimization. For instance, [61] present a global objective function of the form $J=J_{e}+\alpha \cdot J_{d}+\varphi \cdot J_{f}$, which is an EMPC but also taking into account a discomfort term $J_{d}$ with weight $\alpha$ and a flexibility term $J_{f}$ with weight $\varphi$. The MPC controller then tries to minimize J over the receding horizon, taking into account the constraints of the problem. Some terms like $J_{d}$ are not linear (because of the maximum function) and therefore require more numerical efforts for solving. 


\subsection{Accounting for comfort}

Accounting for the users' comfort is a crucial aspect when designing HVAC control strategies, because it will eventually affect the acceptance and thus the viability of such methods. It was observed in the literature that comfort can be included in the MPC toolchain either as a constraint, or as an objective.

As a hard constraint, the comfort requirements take the form of a temperature range in which the indoor temperature (control output) should stay: for example, $22-25^{\circ} \mathrm{C}$ in winter and $22-27^{\circ} \mathrm{C}$ in summer mentioned by [59], $21-24^{\circ} \mathrm{C}$ in [58], $20-22^{\circ} \mathrm{C}$ in [31]. The constraints can be relaxed during non-occupancy periods: in [31], outside the time frame [7:00 - 22:00], the problem is unconstrained. [50] change the constraint at night, with a minimum output temperature of $18^{\circ} \mathrm{C}$, while this lower bound is set to $21^{\circ} \mathrm{C}$ during daytime. The temperature range constraint can also be applied into storage tanks when applicable, for instance when using DHW that needs to be kept above $55^{\circ} \mathrm{C}$ to avoid Legionnaire's disease.

Constraining the optimization problem in such a way makes it impossible to find an explicit solution (numerical methods must be used)[45]. Furthermore, it can happen that the optimizer does not find a solution that respects these constraints (because of the dynamics of the building for example). For these reasons, many authors prefer to integrate the comfort as a term in the objective function: in this way, violations of the comfort requirements are always possible, but they are penalized. This term can take the following form:

$$
J_{d}=\sum_{k} \theta_{o c c}(k) \cdot\left(T_{z o n}(k)-T_{\text {set }}(k)\right)^{2}
$$

With $\theta_{o c c}$ an occupancy factor, $T_{z o n}$ and $T_{\text {set }}$ respectively the actual zone temperature and setpoint. The controller thus has to track the reference set-point $T_{\text {set }}$. The temperature error $T_{z o n}-T_{\text {set }}$ is here considered as squared, which means that large temperature deviations will be more penalized than small ones, but some papers only consider the absolute value of this error. Another remark raised by [58] concerns the use of unconstrained temperature range in real building applications: it might cause problems because the actuators (room thermostats) might have a specific acceptable range of temperature set-points.

Li and Malkawi [47] propose an original approach, using the Predicted Mean Vote (PMV). This indicator reflects the thermal sensation of the occupants and varies from -3 (too cold) to +3 (too hot), while 0 corresponds to a neutral sensation. Aiming to achieve this optimal (neutral) comfort with $\mathrm{PMV}=0$, the comfort term in the objective function is $J_{d}=\sum_{k}\left(\theta_{o c c}(k) \cdot P M V(k)\right)^{2}$. This method enables to keep the PMV within the limits recommended by ASHRAE standard $(-0.5<\mathrm{PMV}<0.5)[63]$ for most of the occupancy time. However, this approach requires a high computation demand (around 3 hours to solve the optimization problem with detailed building simulation), given the complex calculation of the PMV which depends on the occupants' clothing and metabolic rate as well as the indoor temperature and air velocity [64].

\subsection{Other constraints}

Accounting for comfort mainly leads to constraining the control output (indoor temperature), which must be anticipated beforehand by the controller. However, some constraints should also be set to the control inputs, to account for the physical limitations of the devices in use. For instance, [53] bounds the power of the heating system to [0-0.5 kW], and [31] to [0 - $3 \mathrm{~kW}]$, which corresponds to the devices used in their respective studies. The MPC controller can then pick a thermal power within this interval at every time step. In [59] and [60], the MPC also controls blinds or ventilation in addition to the heat pump, therefore constraints are also imposed on these systems (minimum and maximum air supply temperature, only non-closed position for the blinds during occupancy hours to guarantee some daylighting). A minimum air ventilation flow rate is also implemented as a constraint for health reasons, to guarantee air renewal indoors. Sometimes, constraints are also imposed on the changes in the control inputs $u(k+1)-u(k)$, to avoid frequent cycling behavior and increase the controller robustness, like in [50] or [51]. 


\subsection{Challenges in modelling}

One of the greatest challenges residing within MPC is obtaining the model used in the controller. It remains a difficult task to create an accurate model for every building, yet simple enough to limit the computation effort for the controller. Indeed, detailed models (developed for energy calculations for instance) are not commonly used for MPC applications since they drastically increase the computation time required by the optimization solver (example: 3 hours in [47] for the total solving of the optimization problem with EnergyPlus and Genopt). Instead, simplified RC-models (resistance-capacity, analog to electrical models) are utilized in the great majority of the reviewed cases, but they provide less accurate description of the heat dynamics of the building. RC-models have the general form presented in Eq. (7)[62]:

$$
C_{n} T_{n}=\sum_{j} \frac{T_{j}-T_{n}}{R_{j, n}}+\sum_{l} H_{l}
$$

Where $\mathrm{j}$ is the $\mathrm{j}$-th node with temperature $T_{j}, R_{j, n}$ is the thermal resistance between points $\mathrm{j}$ and n, $C_{n}$ and $T_{n}$ are respectively the thermal capacity and temperature of the point of interest, and $W_{l}$ represents the different additional heat fluxes. This form of model is therefore linear and corresponds to a network of thermal capacities and resistances, which can either be assigned to the real elements of the building (interior air, walls, furniture etc...) or be lumped into a reduced order model. Santos et al. [51] experimented the use of non-linear models, expressing some of the thermal resistances $R_{j, n}$ with power laws in function of the wind speed. This non-linear controller proved to be more efficient, especially when the weather conditions are determinant and the non-linearity of the models become essential to describe the dynamics of the system.

Some of the issues related to modelling in MPC are related by [61]. For example, the model of MPC can require a lot of meta-information (like room sizes, insulation level etc.), but these data are often not available. The authors of [61] therefore suggest creating simpler models, so that the method is applicable in a larger number of cases. This can cause some problems: the identification dataset used for the model of [61] was retrieved in January/February, therefore the solar radiation was discarded as a significant input. This situation is not true anymore in the summer season, hence the control model is mainly valid for winter season and this becomes problematic. Several attempts at solving the model inaccuracy issues have been reported in the literature. [31] used a simplified model for the controller, which induced some error. Therefore a feedback loop was implemented from a more detailed emulator, to introduce a correction for the possible mismatch between the simplified model and the emulator.

For obtaining easily a model adapted to a specific building, [65] created a specific toolbox. Its toolchain facilitates and automates the different steps in the system identification procedure like datahandling, model selection, parameter estimation and validation. It was tested for a single-family dwelling for which measured data was available for validation. One experiment showed poorer results and the authors identified a poor information content in the identification dataset as the likely reason.

To create a dataset sufficient for the identification process, [66] proposed a method based on the excitation of the building by a pseudo-random binary sequence signal. This signal applied to the heating system reveals and facilitates the creation of suitable models representing the heat dynamics of buildings. To analyze the obtained time series, the CTSM tool (Continuous Time Stochastic Modelling) has been proposed by [67]. It enables to identify grey-box models using multivariate time series data, and to identify the embedded parameters (thermal resistances and capacities for example).

\subsection{Disturbances}

An MPC controller usually simulates the response of the building model to several external disturbances, not only to the control inputs. The most common disturbances taken into account by MPC are the outside weather conditions, since they will affect the most the heating or cooling needs of the building. The external temperature is considered in the model of almost all the reviewed papers. A notable exception is the paper [58], where the authors found out that the outside 
temperature did not have as much influence on the output as the set-points or the heating power, and therefore neglected it. The articles [54,59-61] only consider the external temperature when accounting for weather conditions. Several papers additionally consider the solar irradiation [50,52,53,62]. Besides the external temperature and the solar irradiation, [51] and [31] also take into account the effects of wind speed. In many cases, it is assumed that the forecast of these disturbances is perfect. When the MPC is implemented in a real building, weather forecast is retrieved from external services or derived from a local measurement.

Another major source of disturbance is the internal heat gains. They group the heat gains from occupants, appliances and equipment. Most commonly, a deterministic approach is applied, with a fixed schedule representing these internal gains [31,52,62]. When the MPC is implemented in real buildings, other methods can be employed: an occupancy sensor like in [54], or deriving the internal gains from measurements of the plug and lighting electricity circuits [61].

For all the EMPC strategies relying on cost optimization, the time-varying price of energy constitutes an additional cost signal to be taken into account by the controller. Time-of-use electricity tariffs are applied most often, with different values for peak periods and off-peak periods, and sometimes with an additional medium price in-between. In other papers, hourly tariffs are applied, reflecting day-ahead prices on the spot market.

Regarding the prediction of the disturbances, different concepts are found in the literature. Several publications consider a perfect knowledge of the future (in the case of simulations), which corresponds to the highest achievable performance of MPC. Most of the time, a forecast of the electricity price and weather for the next 24 hours can be retrieved, which is an imperfect prediction. This solution is implemented in most of the studied papers, especially when the MPC is applied to a real building. Finally, the MPC can also be left without any knowledge of the future, and therefore needs to build its own disturbances' forecast. To this end, one can utilize black-box models using past data. In the case of energy price and weather, an oscillatory behavior with a period of one day is observed. Shaping filters on historic data can be applied, considering a 24 hours period and adding white noise to account for the stochastic behavior. Pawlowski et al. [68] present different time-series methods for estimating disturbance forecasts to be used in MPC. In [55], the authors compare the three approaches (full, imperfect or zero knowledge about the future). With perfect predictions, the EMPC achieves cost reduction of $31 \%$, while with perfect ignorance of the future, the cost reductions amount to $27 \%$. The performance thus improves with a better forecast, but the margin remains relatively small.

\section{Thermal energy storage}

When studying the potential flexibility offered by buildings, the thermal energy storage plays a key role, since it enables to stock energy for later use, hence shifting the loads in time. In general for DSM with heat pumps, two fundamentally different types of thermal storage are considered [24]: building thermal mass and water buffer storage tanks (sometimes they are combined together). In some reviews, the first type is called passive storage whereas the second one is referred to as active storage [69]. Many other types of thermal storage do exist, such as Phase Change Materials (PCM), thermo-chemical or ice storage [70] but most of the studied cases in the present work rely on existing thermal mass and water storage tanks for activating flexibility.

When their storage losses are neglected [55,71,72], water tanks are found to provide greater flexibility. However when these losses are considered [21,29-31,34], larger water tanks induce a degradation in the system efficiency due to these increased thermal losses. Furthermore, water storage tanks are costly in monetary terms and in terms of space occupied within the building.

On the other hand, thermal mass does not require prior investment since it is already available within the construction of the building. However, the comfort constraints are more restrictive because of the limited temperature variations allowed in the occupied zones (which is less problematic in a water tank). Building thermal mass has been identified and tested by several studies as a good storage means for demand-side management and flexibility initiatives [32,35,73,74], but its potential highly 
depends on the type of building [31,32,35]. Further investigations are needed since the existing literature contains some lacks in this regard [35,75].

\section{Discussions}

To summarize, even though RBC strategies can yield significant improvements, they do not achieve the optimal performance. For this reason, MPC has shown strong advantages over classical control, but some challenges remain concerning its implementation. The largest one resides in obtaining a satisfactory building model for the controller, which is a costly and complicated process. A trade-off needs to be found between the accuracy of the model and its simplicity. To tackle this issue, several methods have been developed to facilitate the obtaining of building models to be used by MPC controllers [65-67]. Furthermore, it would be relevant for further studies to include the computation times, so that the efficiency of different modelling approaches can be evaluated.

Another challenge consists in realizing the connection of MPC with different data services. It might result difficult to realize a connection to weather forecast services from a third party; and even if it is realized, the closest forecast might not be adapted to the local conditions. The automatic access to the day-ahead electricity price (in case it is variable) might not either be straightforward. However, the upcoming large implementation of smart meters (the EU aims to replace at least $80 \%$ of electricity meters with smart meters by 2020 wherever it is cost-effective to do so [76] and by 2018 in Spain [77]) could facilitate this communication between the end-consumer and the grid. Moreover, the numerous examples of smart grid projects usually already consider that the users have access to electricity price data.

Despite these potential barriers, MPC has been identified as a very powerful tool to activate energy flexibility and optimize heat pump operation. Globally, MPC overcomes the limitations encountered by simpler rule-based controls and outperforms them [41,78]. MPC projects the behavior of the system in the future, and thus optimizes the heat pump operation over a certain control horizon, for instance storing energy at times where it is more profitable, and releasing it afterwards when needed. The lack of dynamics and anticipation of RBC are therefore clearly surmounted by MPC. From their review about optimal design and control of GSHP, [19] deduced that model-based control methods are better by far than any other approaches and that RBC is suboptimal compared to MPC.

Among the different studies reviewed on MPC, a large majority resorted to Economic Model Predictive Control (EMPC). The primary objective of such strategy is thus to minimize the energy cost. This objective is generally achieved, with reductions of up to $40 \%$ in the reviewed papers and without jeopardizing thermal comfort, compared to conventional heating curve (or cooling curve) control strategies [20]. Reduction of energy use or improvement of the comfort can also occur with EMPC even though they are not formally identified as an objective. In this regard, it would be interesting if further research would analyze the effects of EMPC further than the reduction of the energy cost (which some articles also do). In particular, the correlation of the variable electricity price with the primary energy factors or the $\mathrm{CO}_{2}$ emissions should be studied, so that EMPC can be used for more global objectives than the sole monetary one. In this way, the EMPC framework can be kept, but by adapting the price profile to the desired effect, one can instead achieve a reduction of the primary energy use or the $\mathrm{CO}_{2}$ emissions.

Along the same lines, it should be mentioned that few articles were found with MPC strategies that considered other objectives than the reduction of the energy costs. EMPC seems the most common way to provide energy flexibility, but it has been extensively studied, therefore the research efforts should now concentrate on other aspects. In particular, other objective terms should be integrated in the MPC framework, such as the heat pump COP (coefficient of performance), flexibility indicators or primary energy use. The study [78] notably compares different MPC objectives, concluding that the reduction of the energy use or the maximization of renewable energy use are the most interesting options. If energy flexibility is bound to become the new target for energy efficient buildings [79], then it should be integrated directly as an objective in the optimization problem through different indicators [80], to maximize this flexibility. Furthermore, it would be relevant to 
include multi and contradictory objectives in the same MPC, and evaluate the trade-off made by the controller. For instance, it could seem like a good strategy to operate a heat pump at night to benefit from traditionally lower electricity prices, but the COP is also reduced at night because of lower outdoor temperature (in heating case). These two aspects need to be balanced by the MPC, and it should be noted that rule-based controls can only deal with such issues in an intuitive (non-optimal) manner.

Overall, despite its complexity and the identified challenges residing in the modelling and the implementation of such control, MPC strategies are bound to be increasingly used in the future. [40] put forward several reasons for this foreseen development: drastic increase in computational power, standardized use of simulation tools, increase in the quality of weather forecasting, rising of energy costs and the desire to handle time-varying electricity prices (within smart grids for instance). However, the existing work on MPC for heat pump control primarily relies on simulations; few implementations in real buildings have been realized [30] (see also Table 2). Now that this technology is mature enough, it should be deployed and studied in more realistic environments. In particular, the heat pump functioning in real-time, its efficiency, the part-load conditions, the interactions between supervisory and local controls, the comparison between simulation and experiments have rarely been mentioned in the literature, and thus constitute interesting paths for new investigations. Furthermore, the studied articles often focus on a single heat pump system in one building. Energy flexibility has much greater potential when aggregated for numerous buildings, therefore this aspect should also be studied: multiple MPC algorithms that collaborate to reach a common goal, aggregation potential and drawbacks, impact of market penetration. Several works have already been published on these topics $[30,81]$, but more research is needed.

\section{Conclusions}

In this study, supervisory control strategies for activating energy flexibility with heat pumps have been reviewed, and classified between rule-based controls and Model Predictive Control. The strength of RBC strategies resides in their simplicity of implementation, and they already achieve satisfactory performance, though not optimal. MPC is more complex and costly to integrate, but yields substantially better results. Cost optimization (EMPC) was found to be the most common objective within MPC applications, therefore it is recommended to carry out research work also on other objectives, more related to flexibility. Furthermore, a great majority of the studied literature relies on simulations rather than implementations in real contexts, therefore more experimental work is needed. For activating the energy flexibility of buildings, a thermal storage is necessary; in this regard, building thermal mass was found to be a promising solution compared to buffer tanks.

\section{Nomenclature}

$\begin{array}{cl} & \text { Parameters } \\ E & \text { Thermal capacity } \\ G & \text { Energy consumption } \\ H & \text { Consumption } \\ J & \text { Heat flux } \\ N & \text { Objective function } \\ P & \text { Price } \\ P M V & \text { Predicted Mean Vote } \\ Q & \text { Heat demand } \\ R & \text { Thermal resistance } \\ T & \text { Temperature (operative) } \\ W & \text { Heat pump power } \\ c & \text { Cost vector } \\ k & \text { Time step } \\ u & \text { Control inputs vector } \\ \alpha & \text { Weighting factor }\end{array}$

$\begin{array}{cl} & \text { Subscripts } \\ c & \mathrm{CO}_{2} \text { intensity } \\ d & \text { Discomfort } \\ e & \text { Economic } \\ e l & \text { Electricity } \\ f & \text { Flexibility } \\ g & \text { Natural gas } \\ h p & \text { Heat pump } \\ \text { min } & \text { Minimum } \\ \text { max } & \text { Maximum } \\ \text { occ } & \text { Occupancy } \\ p & \text { Demand peak } \\ \text { pred } & \text { Predicted } \\ q & \text { Energy } \\ r & \text { Control robustness } \\ \text { set } & \text { Set-point } \\ \text { zon } & \text { Zone }\end{array}$


$\theta \quad$ Occupancy factor

$\begin{array}{llll} & \text { Abbreviations } & & \\ \text { COP } & \text { Coefficient of Performance } & \text { PV } & \text { Photovoltaic } \\ \text { DHW } & \text { Domestic Hot Water } & \text { RBC } & \text { Rule-based control } \\ \text { DSM } & \text { Demand-Side Management } & \text { RES } & \text { Renewable Energy Source } \\ \text { GSHP } & \text { Ground-source heat pump } & \text { SOC } & \text { State of Charge } \\ \text { HVAC } & \text { Heating, Ventilation, Air conditioning } & \text { TES } & \text { Thermal Energy Storage } \\ \text { (E)MPC } & \text { (Economic) Model Predictive Control } & \text { ToU } & \text { Time of Use } \\ \text { NRPE } & \text { Non-renewable primary energy } & \text { nZEB } & \text { Nearly Zero Energy Building }\end{array}$

Acknowledgments: This project has received funding from the European Union's Horizon 2020 research and innovation programme under the Marie Skłodowska-Curie grant agreement No 675318 (INCITE). Part of this work stems from the activities carried out in the framework of the IEA-EBC Annex 67 (International Energy Agency - Energy in Buildings and Communities program) about Energy Flexibility in Buildings.

\section{References}

[1] European Parliament, Directive 2009/28/EC on the promotion of the use of energy from renewable sources, Off. J. EU. (2009).

[2] REN 21, Renewables 2016. Global status report, (2016). http://www.ren21.net/wpcontent/uploads/2016/06/GSR_2016_KeyFindings1.pdf.

[3] I. Mareels, J. De Hoog, D. Thomas, M. Brazil, T. Alpcan, D. Jayasuriya, V. Müenzel, L. Xia, R.R. Kolluri, On making energy demand and network constraints compatible in the last mile of the power grid, Annu. Rev. Control. 38 (2014) 243-258. doi:10.1016/j.arcontrol.2014.09.007.

[4] IEA DSM Task 17, Conclusions and Recommendations - Demand Flexibility in Households and Buildings, 2016. http://www.ieadsm.org/publications/key-publications/.

[5] A. Arteconi, N.J. Hewitt, F. Polonara, Domestic demand-side management (DSM): Role of heat pumps and thermal energy storage (TES) systems, Appl. Therm. Eng. 51 (2013) 155-165. doi:10.1016/j.applthermaleng.2012.09.023.

[6] L. Igualada, C. Corchero, M. Cruz-Zambrano, F.J. Heredia, Optimal energy management for a residential microgrid including a vehicle-to-grid system, IEEE Trans. Smart Grid. 5 (2014) 2163-2172. doi:10.1109/TSG.2014.2318836.

[7] S.Ø. Jensen, A. Marszal-Pomianowska, R. Lollini, W. Pasut, A. Knotzer, P. Engelmann, A. Stafford, G. Reynders, IEA EBC Annex 67 Energy Flexible Buildings, Energy Build. 155 (2017) 25-34. doi:10.1016/j.enbuild.2017.08.044.

[8] European Commission, Directive 2010/31/EU of the European Parliament and of the Council of 19 May 2010 on the energy performance of buildings (recast), Off. J. Eur. Communities. L 153 (2010) 13-35.

[9] A.J. Marszal, P. Heiselberg, J.S. Bourrelle, E. Musall, K. Voss, I. Sartori, A. Napolitano, Zero Energy Building - A review of definitions and calculation methodologies, Energy Build. 43 (2011) 971-979. doi:10.1016/j.enbuild.2010.12.022.

[10] I. Sartori, A. Napolitano, K. Voss, Net zero energy buildings: A consistent definition framework, Energy Build. 48 (2012) 220-232. doi:10.1016/j.enbuild.2012.01.032.

[11] J. Salom, A.J. Marszal, J. Widén, J. Candanedo, K.B. Lindberg, Analysis of load match and grid interaction indicators in net zero energy buildings with simulated and monitored data, Appl. Energy. 136 (2014) 119-131. doi:10.1016/j.apenergy.2014.09.018. 
[12] J. Salom, J. Widén, J. Candanedo, K.B. Lindberg, Analysis of grid interaction indicators in net zeroenergy buildings with sub-hourly collected data, Adv. Build. Energy Res. 136 (2014) 1-18. doi:10.1080/17512549.2014.941006.

[13] J. Salom, J. Widén, J. a Candanedo, I. Sartori, K. Voss, A.J. Marszal, Understanding Net Zero Energy Buildings: Evaluation of load matching and grid interaction indicators, Proc. Build. Simul. 2011. 6 (2011) 14-16. doi:ISBN: 9870646565101.

[14] F. Noris, E. Musall, J. Salom, B. Berggren, S.Ø. Jensen, K. Lindberg, I. Sartori, Implications of weighting factors on technology preference in net zero energy buildings, Energy Build. 82 (2014) 250-262. doi:10.1016/j.enbuild.2014.07.004.

[15] E. Rodriguez-Ubinas, C. Montero, M. Porteros, S. Vega, I. Navarro, M. Castillo-Cagigal, E. Matallanas, A. Gutierrez, Passive design strategies and performance of Net Energy Plus Houses, Energy Build. 83 (2014) 10-22. doi:10.1016/j.enbuild.2014.03.074.

[16] T.Q. Péan, L. Gennari, O.B. Kazanci, B.W. Olesen, Evaluation of the Energy and Comfort Performance of a Plus- Energy House under Scandinavian Summer Conditions, Proc. 12th World REHVA Conf. CLIMA 2016, Aalborg, Denmark. (2016).

[17] Y.J. Kim, E. Fuentes, L.K. Norford, Experimental Study of Grid Frequency Regulation Ancillary Service of a Variable Speed Heat Pump, IEEE Trans. Power Syst. 31 (2016) 3090-3099. doi:10.1109/TPWRS.2015.2472497.

[18] A. Afram, F. Janabi-Sharifi, Theory and applications of HVAC control systems - A review of model predictive control (MPC), Build. Environ. 72 (2014) 343-355. doi:10.1016/j.buildenv.2013.11.016.

[19] E. Atam, L. Helsen, Ground-coupled heat pumps: Part 1 - Literature review and research challenges in modeling and optimal control, Renew. Sustain. Energy Rev. 54 (2016) 1653-1667.

doi:10.1016/j.rser.2015.10.007.

[20] D. Fischer, H. Madani, On heat pumps in smart grids: A review, Renew. Sustain. Energy Rev. 70 (2017) 342-357. doi:10.1016/j.rser.2016.11.182.

[21] K.-H. Lee, M.-C. Joo, N.-C. Baek, Experimental Evaluation of Simple Thermal Storage Control Strategies in Low-Energy Solar Houses to Reduce Electricity Consumption during Grid On-Peak Periods, Energies. 8 (2015) 9344-9364. doi:10.3390/en8099344.

[22] J. Hong, C. Johnstone, J. Torriti, M. Leach, Discrete demand side control performance under dynamic building simulation: A heat pump application, Renew. Energy. 39 (2012) 85-95. doi:10.1016/j.renene.2011.07.042.

[23] H. Madani, J. Claesson, P. Lundqvist, A descriptive and comparative analysis of three common control techniques for an on/off controlled Ground Source Heat Pump (GSHP) system, Energy Build. 65 (2013) 1-9. doi:10.1016/j.enbuild.2013.05.006.

[24] M. Miara, D. Günther, Z.L. Leitner, J. Wapler, Simulation of an Air-to-Water Heat Pump System to Evaluate the Impact of Demand-Side-Management Measures on Efficiency and Load-Shifting Potential, Energy Technol. 2 (2014) 90-99. doi:10.1002/ente.201300087.

[25] C. Kandler, P. Wimmer, J. Honold, Predictive control and regulation strategies of air-to-water heat pumps, Energy Procedia. 78 (2015) 2088-2093. doi:10.1016/j.egypro.2015.11.239.

[26] C. Verhelst, Model Predictive Control of Ground Coupled Heat Pump Systems for Office Buildings, Katholieke Universiteit Leuven, 2012. 
[27] U.I. Dar, I. Sartori, L. Georges, V. Novakovic, Advanced control of heat pumps for improved flexibility of Net-ZEB towards the grid, Energy Build. 69 (2014) 74-84. doi:10.1016/j.enbuild.2013.10.019.

[28] ISO, ISO 7726: Ergonomics of the thermal environment - Instruments for measuring physical quantities, 2001.

[29] R. De Coninck, R. Baetens, B. Verbruggen, J. Driesen, D. Saelens, L. Helsen, Modelling and simulation of a grid connected photovoltaic heat pump system with thermal energy storage using Modelica, 8th Int. Conf. Syst. Simul. Build. (2010) 1-21.

[30] R. De Coninck, R. Baetens, D. Saelens, A. Woyte, L. Helsen, Rule-based demand-side management of domestic hot water production with heat pumps in zero energy neighbourhoods, J. Build. Perform. Simul. 7 (2014) 271-288. doi:10.1080/19401493.2013.801518.

[31] G. Masy, E. Georges, C. Verhelst, V. Lemort, Smart grid energy flexible buildings through the use of heat pumps and building thermal mass as energy storage in the Belgian context, Sci. Technol. Built Environ. 4731 (2015) 800-811. doi:10.1080/23744731.2015.1035590.

[32] G. Reynders, T. Nuytten, D. Saelens, Potential of structural thermal mass for demand-side management in dwellings, Build. Environ. 64 (2013) 187-199. doi:10.1016/j.buildenv.2013.03.010.

[33] A.D. Carvalho, P. Moura, G.C. Vaz, A.T. De Almeida, Ground source heat pumps as high efficient solutions for building space conditioning and for integration in smart grids, Energy Convers. Manag. 103 (2015) 991-1007. doi:10.1016/j.enconman.2015.07.032.

[34] L. Schibuola, M. Scarpa, C. Tambani, Demand response management by means of heat pumps controlled via real time pricing, Energy Build. 90 (2015) 15-28. doi:10.1016/j.enbuild.2014.12.047.

[35] J. Le Dréau, P. Heiselberg, Energy flexibility of residential buildings using short term heat storage in the thermal mass, Energy. 111 (2016) 1-5. doi:10.1016/j.energy.2016.05.076.

[36] G.R. Newsham, B.G. Bowker, The effect of utility time-varying pricing and load control strategies on residential summer peak electricity use: A review, Energy Policy. 38 (2010) 3289-3296.

doi:10.1016/j.enpol.2010.01.027.

[37] O. Corradi, H. Ochsenfeld, Integration of fluctuating energy by electricity price control, Technical University of Denmark (DTU), 2011.

[38] K. Klein, S. Killinger, D. Fischer, C. Streuling, J. Salom, E. Cubi, Comparison of the future residual load in fifteen countries and requirements to grid-supportive building operation, in: Eurosun 2016, Palma (Mallorca), Spain, 2016: pp. 11-14.

[39] T. Péan, J. Ortiz, J. Salom, Impact of Demand-Side Management on Thermal Comfort and Energy Costs in a Residential nZEB, Buildings. 7 (2017) 37. doi:10.3390/buildings7020037.

[40] F. Oldewurtel, A. Parisio, C.N. Jones, D. Gyalistras, M. Gwerder, V. Stauch, B. Lehmann, M. Morari, Use of model predictive control and weather forecasts for energy efficient building climate control, Energy Build. 45 (2012) 15-27. doi:10.1016/j.enbuild.2011.09.022.

[41] D. Fischer, J. Bernhardt, H. Madani, C. Wittwer, Comparison of control approaches for variable speed air source heat pumps considering time variable electricity prices and PV, Appl. Energy. 204 (2017) 93105. doi:10.1016/j.apenergy.2017.06.110.

[42] M. del M. Castilla, J.D. Álvarez, F. Rodríguez, M. Berenguel, Comfort Control in Buildings, Springer London, London, 2014. doi:10.1007/978-1-4471-6347-3.

[43] Y. Zong, L. Mihet-Popa, D. Kullmann, A. Thavlov, O. Gehrke, H.W. Bindner, Model predictive 
controller for active demand side management with PV self-consumption in an intelligent building, IEEE PES Innov. Smart Grid Technol. Conf. Eur. (2012) 1-8. doi:10.1109/ISGTEurope.2012.6465618.

[44] C. Verhelst, D. Degrauwe, F. Logist, J. Van Impe, L. Helsen, Multi-objective optimal control of an airto-water heat pump for residential heating, Build. Simul. 5 (2012) 281-291. doi:10.1007/s12273-0120061-z.

[45] E.F. Camacho, C. Bordons, Model Predictive control, Springer London, London, 2007. doi:10.1007/9780-85729-398-5.

[46] F. Tahersima, J. Stoustrup, H. Rasmussen, S. a. Meybodi, Economic COP optimization of a heat pump with hierarchical model predictive control, 2012 IEEE 51st IEEE Conf. Decis. Control. (2012) 7583-7588. doi:10.1109/CDC.2012.6425810.

[47] X. Li, A. Malkawi, Multi-objective optimization for thermal mass model predictive control in small and medium size commercial buildings under summer weather conditions, Energy. 112 (2016) 1194-1206. doi:10.1016/j.energy.2016.07.021.

[48] T.S. Pedersen, P. Andersen, K.M. Nielsen, Central control of heat pumps for smart grid purposes tested on single family houses, 2013 10th IEEE Int. Conf. Networking, Sens. Control. ICNSC 2013. (2013) 118-123. doi:10.1109/ICNSC.2013.6548722.

[49] M.U. Kajgaard, J. Mogensen, A. Wittendorff, A.T. Veress, B. Biegel, Model predictive control of domestic heat pump, 2013 Am. Control Conf. (2013) 2013-2018. doi:10.1109/ACC.2013.6580131.

[50] R. Halvgaard, N.K. Poulsen, H. Madsen, J.B. Jorgensen, Economic Model Predictive Control for building climate control in a Smart Grid, 2012 IEEE PES Innov. Smart Grid Technol. (2012) 1-6. doi:10.1109/ISGT.2012.6175631.

[51] R.M. Santos, Y. Zong, J. Sousa, L. Mendonça, A. Thavlov, Nonlinear Economic Model Predictive Control Strategy for Active Smart Buildings, in: 2016. doi:978-1-5090-3358-4/.

[52] G. Bianchini, M. Casini, A. Vicino, D. Zarrilli, Demand-response in building heating systems: A Model Predictive Control approach, Appl. Energy. 168 (2016) 159-170. doi:10.1016/j.apenergy.2016.01.088.

[53] M. Dahl Knudsen, S. Petersen, Demand response potential of model predictive control of space heating based on price and carbon dioxide intensity signals, Energy Build. 125 (2016) 196-204. doi:10.1016/j.enbuild.2016.04.053.

[54] S.M. Sichilalu, X. Xia, Optimal power dispatch of a grid tied-battery-photovoltaic system supplying heat pump water heaters, Energy Convers. Manag. 102 (2015) 81-91.

doi:10.1016/j.enconman.2015.03.087.

[55] D.I. Mendoza-Serrano, D.J. Chmielewski, Smart grid coordination in building HVAC systems: EMPC and the impact of forecasting, J. Process Control. 24 (2014) 1301-1310. doi:10.1016/j.jprocont.2014.06.005.

[56] J. Salpakari, P. Lund, Optimal and rule-based control strategies for energy flexibility in buildings with PV, Appl. Energy. 161 (2016) 425-436. doi:10.1016/j.apenergy.2015.10.036.

[57] H.A. Toersche, V. Bakker, A. Molderink, S. Nykamp, J.L. Hurink, G.J.M. Smit, Controlling the heating mode of heat pumps with the TRIANA three step methodology, 2012 IEEE PES Innov. Smart Grid Technol. ISGT 2012. (2012) 1-7. doi:10.1109/ISGT.2012.6175662.

[58] J. Ma, S.J. Qin, T. Salsbury, Application of economic MPC to the energy and demand minimization of a commercial building, J. Process Control. 24 (2014) 1282-1291. doi:10.1016/j.jprocont.2014.06.011. 
[59] D. Sturzenegger, D. Gyalistras, M. Gwerder, C. Sagerschnig, M. Morari, R.S. Smith, Model Predictive Control of a Swiss office building, in: 11th REHVA World Congr., 2013: p. 10. http://www.opticontrol.ethz.ch/Lit/Stur_13_Proc-Clima2013.pdf.

[60] F. Oldewurtel, D. Sturzenegger, G. Andersson, M. Morari, R.S. Smith, Towards a standardized building assessment for demand response, Proc. IEEE Conf. Decis. Control. (2013) 7083-7088. doi:10.1109/CDC.2013.6761012.

[61] R. De Coninck, L. Helsen, Practical implementation and evaluation of model predictive control for an office building in Brussels, Energy Build. 111 (2016) 290-298. doi:10.1016/j.enbuild.2015.11.014.

[62] Z. Váňa, J. Cigler, J. Široký, E. Žáčeková, L. Ferkl, Model-based energy efficient control applied to an office building, J. Process Control. 24 (2014) 790-797. doi:10.1016/j.jprocont.2014.01.016.

[63] ASHRAE, ANSI/ASHRAE Standard 55: Thermal Environmental Conditions for Human Occupancy., Ashrae. (2013). doi:ISSN 1041-2336.

[64] UNE, ISO 7730: Ergonomics of the thermal environment - Analytical determination and interpretation of thermal comfort using calculation of the PMV and PPD indices and local thermal comfort criteria., (2006).

[65] R. De Coninck, F. Magnusson, J. Åkesson, L. Helsen, Toolbox for development and validation of greybox building models for forecasting and control, J. Build. Perform. Simul. (2015) 1-16. doi:10.1080/19401493.2015.1046933.

[66] P. Bacher, H. Madsen, Identifying suitable models for the heat dynamics of buildings, Energy Build. 43 (2011) 1511-1522. doi:10.1016/j.enbuild.2011.02.005.

[67] R. Juhl, J.K. Møller, H. Madsen, ctsmr - Continuous Time Stochastic Modeling in R, XX (2015) 1-11.

[68] A. Pawlowski, J.L. Guzman, F. Rodríguez, M. Berenguel, J. Sanchez, Application of time-series methods to disturbance estimation in predictive control problems, IEEE Int. Symp. Ind. Electron. (2010) 409-414. doi:10.1109/ISIE.2010.5637867.

[69] R. Ooka, S. Ikeda, A review on optimization techniques for active thermal energy storage control, Energy Build. 106 (2015) 225-233. doi:10.1016/j.enbuild.2015.07.031.

[70] A. Arteconi, N.J. Hewitt, F. Polonara, State of the art of thermal storage for demand-side management, Appl. Energy. 93 (2012) 371-389. doi:10.1016/j.apenergy.2011.12.045.

[71] D. Six, J. Desmedt, J.V.A.N. Bael, D. Vanhoudt, Exploring the Flexibility Potential of Residential Heat Pumps, 21st Int. Conf. Electr. Distrib. (2011) 6-9.

[72] D. Vanhoudt, D. Geysen, B. Claessens, F. Leemans, L. Jespers, J. Van Bael, An actively controlled residential heat pump: Potential on peak shaving and maximization of self-consumption of renewable energy, Renew. Energy. 63 (2014) 531-543. doi:10.1016/j.renene.2013.10.021.

[73] H. Wolisz, H. Harb, P. Matthes, R. Streblow, D. Müller, Dynamic simulation of thermal capacity and charging / discharging performance for sensible heat storage in building wall mass, in: 13th Conf. Int. Build. Perform. Simul. Assoc., 2013: pp. 2716-2723.

[74] J. Kensby, A. Trüschel, J.-O. Dalenbäck, Potential of residential buildings as thermal energy storage in district heating systems - Results from a pilot test, Appl. Energy. 137 (2015) 773-781. doi:10.1016/j.apenergy.2014.07.026.

[75] N.J. Hewitt, Heat pumps and energy storage - The challenges of implementation, Appl. Energy. 89 (2012) 37-44. doi:10.1016/j.apenergy.2010.12.028. 
[76] European Parliament, Directive 2009/72/EC of the European Parliament and of the Council of 13 July 2009 concerning common rules for the internal market in electricity, Strasbourg, France, 2009.

[77] Spain, Real Decreto 1110/2007, de 24 de agosto, por el que se aprueba el Reglamento unificado de puntos de medida del sistema eléctrico., (2007).

[78] A. Vandermeulen, L. Vandeplas, D. Patteeuw, Flexibility offered by residential floor heating in a smart grid context : the role of heat pumps and renewable energy sources in optimization towards different objectives ., in: 12th IEA Heat Pump Conf. 2017, 2017: pp. 1-12.

[79] E. Mlecnik, Goodbye Passive House, Hello Energy Flexible Building?, in: Proc. PLEA 2016 36th Int. Conf. Passiv. Low Energy Archit., Los Angeles, USA, 2016.

[80] R.A. Lopes, A. Chambel, J. Neves, D. Aelenei, J. Martins, A Literature Review of Methodologies Used to Assess the Energy Flexibility of Buildings, Energy Procedia. 91 (2016) 1053-1058. doi:10.1016/j.egypro.2016.06.274.

[81] A. Arteconi, D. Patteeuw, K. Bruninx, E. Delarue, W. D’haeseleer, L. Helsen, Active demand response with electric heating systems: Impact of market penetration, Appl. Energy. 177 (2016) 636-648. doi:10.1016/j.apenergy.2016.05.146. 
Appendix

Table A.3. Detailed table of the objective functions.

\begin{tabular}{|c|c|c|c|c|c|c|c|c|c|c|}
\hline Reference & $\begin{array}{l}\text { Objective } \\
\text { function }\end{array}$ & Economic term & Energy term & & Peak shaving term & $\mathrm{CO}_{2}$ term & Robustness term/slack variable & $\begin{array}{l}\text { Flexibility } \\
\text { term }\end{array}$ & & (Dis)comfort term \\
\hline Masy et al. (2015) & $J=$ & $\sum_{k} P_{e l}(k) \cdot W_{h p}(k)$ & & & & & & & $+\alpha$. & $\sum \theta_{o c c}(k) \cdot\left(\varepsilon_{\min }(k)+\varepsilon_{\max }(k)\right)$ \\
\hline $\begin{array}{l}\text { Tahersima et al. } \\
\text { (2012) }\end{array}$ & $J=$ & $\sum_{k}^{n} P_{e l}(k) \cdot T_{\text {sup }}(k)$ & & & & & & & + & $\sum_{k}\left|T_{z o n}(k)-T_{\text {set }}(k)\right|$ \\
\hline $\begin{array}{l}\text { Li and Malkawi } \\
\text { (2016) }\end{array}$ & $J=$ & $\sum_{k} G_{g}(k) P_{g}(k)+P_{e l}(k) W_{h p}(k)$ & & & & & & & $+\alpha$ & $\sum_{k}\left(\theta_{o c c}(k) \cdot P M V(k)\right)^{2}$ \\
\hline $\begin{array}{l}\text { Verhelst et al. } \\
\text { (2012) }\end{array}$ & $J=(1-\alpha)$ & $\sum_{k}^{n} P_{e l}(k) \cdot W_{h p}(k)$ & & & & & & & $+\alpha$ & $\sum_{k}^{n}\left(T_{\text {zon }}(k)-T_{\text {set }}(k)\right)^{2}$ \\
\hline $\begin{array}{l}\text { Pedersen et al. } \\
\text { (2013) }\end{array}$ & $J=$ & $\sum_{k=1}^{24} E_{h p}(k) \mathrm{P}_{e l}(k)$ & & & & & & & + & $\sum_{k=1}^{24}\left|T_{r e f}(k)-T(k)\right| \alpha(k)$ \\
\hline $\begin{array}{l}\text { Kajgaard et al. } \\
\text { (2011) }\end{array}$ & $J=$ & $\alpha \sum_{k} P_{e l}(k) \cdot W_{h p}(k)$ & & + & & & $\sum_{k} l_{\text {int }}(x(k))$ & & + & $\sum_{k} l_{\text {comf }}\left(T_{\text {zon }}(k)-T_{\text {set }}\right)$ \\
\hline $\begin{array}{l}\text { Halvgaard et al. } \\
\text { (2012) }\end{array}$ & $J=$ & $\sum_{k} c(k) \cdot u(k)$ & & + & & & $\sum_{k}^{n} \rho \cdot v(k)$ & & & \\
\hline $\begin{array}{l}\text { Santos et al. } \\
(2016)\end{array}$ & $J=$ & $\sum_{k} c(k) \cdot u(k)$ & & + & & & $\sum_{k}^{N} \rho \cdot v(k)$ & & & \\
\hline $\begin{array}{l}\text { Bianchini et al. } \\
\text { (2016) }\end{array}$ & $J=$ & $\sum_{k}^{k} P_{e l}(k) \cdot W_{h p}(k)$ & & - & & & & $\sum_{j} \gamma_{j} R_{j}$ & & \\
\hline $\begin{array}{l}\text { Knudsen and } \\
\text { Petersen (2016) }\end{array}$ & $J=(1-\alpha)$ & $\sum_{k}^{n} c(k) \cdot u(k)$ & & $+\beta$. & & $\sum_{k} e(k) \cdot u(k)$ & & & & \\
\hline $\begin{array}{l}\text { Sichilalu et al. } \\
\text { (2015) }\end{array}$ & $J=$ & $\sum_{k}^{n}\left(\alpha \cdot P_{e l}(k) \cdot W_{\text {cons }}(k)-\beta \cdot P_{e l} \cdot W_{\text {prod }}(k)\right)$ & & & & & & & & \\
\hline $\begin{array}{l}\text { Mendoza-Serrano } \\
\text { et al. (2014) }\end{array}$ & $J=$ & $\sum_{k} P_{e l}(k) \cdot W_{h p}(k) \cdot \Delta t$ & & & & & & & & \\
\hline $\begin{array}{l}\text { Salpakari and } \\
\text { Lund (2015) }\end{array}$ & $J=$ & $\sum_{k}^{k} P_{e l, n e t}(k) \cdot W_{n e t}(k)$ & & & & & & & & \\
\hline $\begin{array}{l}\text { Toersche et al. } \\
\text { (2012) }\end{array}$ & $J=$ & & & & $\sum_{k=2}^{N}\left|\sum_{j=1}^{H} W_{h p}(k, j)-\sum_{j=1}^{H} W_{h p}(k-1, j)\right|$ & & & & & \\
\hline Ma et al. (2014) & $J=$ & $\sum_{k} P_{e l}(k) \cdot W_{h p}(k) \cdot \Delta t$ & & + & $P_{p} \cdot \max \{W(k)\}$ & & & & & \\
\hline $\begin{array}{l}\text { Sturzenegger et } \\
\text { al. (2013) }\end{array}$ & $J=$ & & $\sum_{k} c(k) \cdot u(k)$ & & & & & & & \\
\hline $\begin{array}{l}\text { Oldewurtel et al. } \\
\text { (2013) }\end{array}$ & $J=$ & & $\sum_{k} c(k) \cdot u(k)$ & & & & & & & \\
\hline $\begin{array}{l}\text { De Coninck et al. } \\
(2016)\end{array}$ & $J=$ & $\sum_{k} G_{g}(k) P_{g}(k)+P_{e l}(k) W_{h p}(k)$ & & $+\alpha$ & & & & $\left(E-E_{\text {target }}\right)^{2}$ & $+\beta$ & $\sum_{k} \theta_{o c c}(k) \cdot\left(T_{z o n}(k)-T_{\text {set }}(k)\right)^{2}$ \\
\hline Vana et al. (2014) & $J=$ & $\sum_{k} c(k) \cdot u(k)$ & & + & & & $\sum_{k} \beta \cdot|u(k)-u(k-1)-v(k)|_{2}^{2}$ & & + & $\sum_{k}\left(|A(y(k)-z(k))|_{2}^{2}+\left|A^{c}\left(y(k)-z^{c}(k)\right)\right|_{2}^{2}\right)$ \\
\hline
\end{tabular}

As far as possible, the terms used in each referenced article were homogenized using the common nomenclature. However some terms were not introduced in the text:

- $\alpha$ 's and $\beta^{\prime}$ s are weighing factors to balance between the different objectives

- In Masy et al. (2015)[31], $\varepsilon_{\text {low }}$ and $\varepsilon_{\text {high }}$ are used to soften the constraints as follows: $T_{\min }-\varepsilon_{\min } \leq T_{z o n} \leq T_{\max }+\varepsilon_{\max }$

- In Pedersen et al. (2013)[48], $\alpha(k)$ is a vector of factors that weight between cost and discomfort

- In Kajgaard et al. (2011)[49], $l_{\text {comf }}$ and $l_{\text {int }}$ are convex cost functions used for comfort (the former uses the temperature error, the latter the integral of that error).

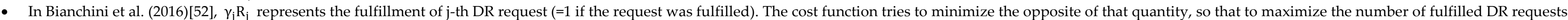

- In Toersche et al. (2012)[57], the double sum corresponds to the successive changes in the energy use. Minimizing this term enables to flatten the energy use profile.

- In Vana et al. (2014)[62], $A$ and $A^{c}$ define two different comfort ranges: one that can be violated from time to time (with a low cost), and a stricter one that should not be violated at almost any time (with a high cost). 